\title{
Internet y los centros de información: aplicaciones, retos y oportunidades
}

\author{
Isabel Ortega Vaquero
}

Centro de Documentación del IAPH

\section{Introducción}

De forma genérica, podemos establecer una doble vía en el uso de Internet en los Centros de Información, entendidos en sentido amplio.

La primera relación se establece como forma de acceso desde el centro a los recursos de información existentes en la Red: documentos, bases de datos, publicaciones, catálogos, informes, servicios de información, etc. Internet es considerada como una gran fuente de información para la mejora de la gestión del organismo y cuya utilización cualifica, potencialmente, las funciones que se desarrollan en el centro. Es decir, el centro de información como usuario de los recursos y de los servicios disponibles en Internet.

La segunda vertiente presenta a la Red como una forma de comunicación y promoción del centro, a través de la producción y difusión de sus recursos y servicios de información: consultas y peticiones electrónicas, nuevos servicios de referencia, organización de recursos externos de interés, edición electrónica de documentos, uso del correo electrónico como nueva plataforma de comunicación, listas de distribución, etc. Es decir, el centro de información como productor y distribuidor de recursos y servicios de información en Internet.

Los objetivos básicos y generales que se plantean son, en primer lugar, la utilización de Internet en todos y cada uno de los procesos informativos que se desarrollen en el centro, ofreciendo la información institucional, catálogos, bases de datos, publicaciones, información temática y especializada, etc. En segundo lugar, la explotación de la información existente en la Red, posibilitando la utilización eficaz y fiable de los recursos de interés sobre nuestro ámbito temático, y de otros recursos generales de información.

Una de las metas iniciales de la conexión a Internet ha sido la accesibilidad a los recursos disponibles en la Red. Sin embargo, cada día, se plantea una nueva perspectiva, enfocada a la producción, organización y difusión de la información propia, así como a la estructuración de la información externa de interés en nuestro ámbito de actuación.

La tendencia actual es el modelo de Servicio de Información Digital, donde tienen cabida todas las fa- ses del proceso documental, incluidas la selección de documentos electrónicos, la descripción de los documentos web mediante metadatos, la normalización de la presentación de información en la red, la evaluación de recursos, etc., con el objetivo de aprovechar todos los recursos a nuestro alcance y llevar a cabo una gestión integral de la información, adoptando un papel activo en la producción y difusión de la información.

Además, se concibe Internet como herramienta de comunicación interinstitucional, posibilitando los medios de comunicación con los usuarios, así como con otras instituciones y organismos públicos y de investigación. Es una solución a los problemas de conexión de instituciones independientes pero homólogas, de lo que se deduce la conveniencia de utilizar Internet como un foro común de diálogo entre las distintas instituciones.

La incidencia de Internet ha modificado la gestión de la información, transformando el entorno, la planificación, la administración y la gestión de los centros, a nivel organizativo, tecnológico y humano. En concreto, el acceso y utilización de las principales aplicaciones y recursos de Internet ha originado importantes cambios $y$ avances en:

\section{Espacio}

El aspecto y la distribución física del espacio se transforman, ya que los documentos ocuparán cada vez menos sitio a favor de los equipamientos tecnológicos. Internet ha roto las fronteras de espacio y tiempo, pasando de un punto de encuentro delimitado a un nuevo espacio universal, virtual, sin horarios, ni cortapisas geográficas, lo que nos lleva a un replanteamiento en la planificación y usos del edificio, de las instalaciones y de las infraestructuras.

\section{Selección y adquisición documental}

La adquisición de materiales impresos se encuentra totalmente modificada por los nuevos formatos accesibles en línea, que facilitan las tareas de identificación y selección, y agilizan ciertos trámites como pedidos o compras a través del Web y del correo electrónico. Asimismo, la expansión de Internet posibilita la selección y la inclusión de recursos electrónicos dentro de las colecciones: la colección digital.

Solicitud de adquisiciones. La implantación de formularios de solicitud de adquisiciones en nuestra página web permite a los usuarios autorizados realizar al centro peticiones de adquisición de nuevas publicaciones, 
y además garantiza la procedencia de la solicitud a través de la dirección de correo electrónico del usuario. Las ventajas son claras: ahorra desplazamientos al usuario y el centro dispone de las solicitudes perfectamente ordenadas para su valoración.

Solicitud de información para las adquisiciones. Son numerosos los recursos existentes para realizar de forma más económica y rápida las tareas de identificación, selección y adquisición de documentos impresos. Muchas bibliografías comerciales, editoriales, distribuidores y librerías se encuentran en el web, además del listado de publicaciones de muchas administraciones públicas. Permiten identificar publicaciones, conocer los precios y su disponibilidad, e incluso algunas ofrecen servicios de envío periódico de novedades por correo electrónico.

Compras. Podemos realizar un pedido de forma rápida y efectuar una compra. El sistema más sencillo de realizar una compra electrónica es enviar el pedido a la dirección de correo electrónico del vendedor. Actualmente, muchas editoriales y librerías han desarrollado formularios para comprar directamente desde la página web, indicando el número de cuenta o el de la tarjeta de crédito.

Desarrollo de la colección digital. El desarrollo de las tecnologías de la información y la expansión de la red Internet posibilitan la inclusión de los recursos electrónicos dentro de las colecciones. Actualmente, los conceptos de localización física, de lo tangible y de la propiedad ya no son determinantes.

Partiendo de la idea de que el centro de información no termina donde acaba su espacio físico, se han comenzado a ofrecer fondos ajenos como parte de la colección propia. Entre éstos se encuentra un gran número de publicaciones electrónicas, ya sean gratuitas o de pago, a las que se puede acceder de forma directa o través de las tradicionales empresas de suscripción, que han ampliado su oferta comercial hacia las revistas electrónicas, al igual que la prensa. De esta manera, se ofrece la posibilidad de consultar de forma remota publicaciones que de otro modo serían difíciles de mantener en una biblioteca.

Se plantea un cambio en la política de adquisiciones hacia el desarrollo de la colección digital, originado por la gran cantidad de documentos electrónicos en texto completo y por la oferta de servicios de alerta electrónica y suministro de copia del documento. Ello modifica el carácter de colección impresa, con la consiguiente sustitución de determinadas adquisiciones en papel, principalmente publicaciones periódicas, y con una selección más rigurosa de los materiales impresos de acuerdo con el uso más frecuente de éstos. Este aspecto está potenciado por los actuales problemas económicos y de espacio, aunque discutido por sus incidencias en el mercado de la información, en los hábitos culturales de los usuarios y por los problemas relacionados con la permanencia y conservación de los recursos digitales.

\section{Análisis documental}

Las tareas tradicionales de descripción bibliográfica se han agilizado con la consulta de bases de datos remotas. Sin embargo, la inclusión de recursos electrónicos en las colecciones, y la proliferación de la información introducida en la Red plantea la necesidad de sistemas que permitan la organización, acceso y conservación de esta información: catalogación, indización y evaluación de recursos digitales.

Catalogación de la colección impresa. La catalogación de los documentos adquiridos y coleccionados localmente se agiliza con la consulta en línea de catálogos de bibliotecas, bibliografías nacionales, etc., de los grandes centros catalográficos para las siguientes aplicaciones: consulta en línea, para resolver dudas de catalogación; catalogación por copia, nos permite descargar registros en nuestro sistema o copiarlos desde registros capturados electrónicamente e impresos posteriormente; y concreciones de catalogación.

Catalogación de documentos electrónicos. Mención aparte merece el control, clasificación y acceso de documentos electrónicos accesibles en red local o remota, que obligará a efectuar cambios en la forma de catalogar y de formar a los profesionales. Por un lado, para que la colección digital pueda entenderse como parte de la colección ha de pasar por un proceso de selección y control bibliográfico, debe integrarse en la estructura bibliográfica de la biblioteca, es decir, debe catalogarse y pasar a formar parte del catálogo.

En este sentido, la OCLC pone en funcionamiento en 1993 el Internet Resource Project para investigar la adecuación de las reglas de catalogación y del formato MARC a los recursos electrónicos distribuidos a través de las redes. Como resultado, el formato USMARC fue ampliado y modificado para la descripción de estos documentos y, en 1995, la OCLC empieza a impulsar la creación de registros MARC de recursos electrónicos con el Internet Cataloging Project $<$ http://www.oclc.org/oclc/man/catproj/catcall.htm>

Para la catalogación aplicada a materiales en línea se puede consultar la sede de la IFLA <http://www. ifla.org $>$, donde hay abundante información sobre la aplicación de las AACR2 y del formato MARC a esta clase de materiales.

También, la creación de páginas web para ordenar el acceso a estos recursos es una nueva forma de catalogar. En este sentido, es muy interesante la experiencia de OCLC en el proyecto CORC (Cooperative Online Resource Catalog) para la creación de un catálogo colectivo de recursos de Internet, diseñado de acuerdo con el formato MARC y los metadatos <http:// www.oclc.org/corc/s.

\section{Búsqueda y recuperación}

Internet supone un cambio significativo en la forma de acceso a la información. Se han ampliado las posibili- 
dades de búsqueda, acceso y consulta de las fuentes de información, que ya no sólo se reduce a información textual sino también a todo tipo de información multimedia (imágenes, vídeo, películas, etc.). Además, los interfaces de búsqueda son mucho más amigables y fáciles de utilizar por el usuario final.

Los servicios de información son uno de los aspectos que más profundamente se ha visto afectado por el desarrollo de Internet.

Consulta de fuentes de información. Internet es una potente fuente de información de referencia, que posibilita un gran abanico de opciones para orientar al usuario sin necesidad de adquirir costosas obras de referencia, aunque no siempre la calidad de la información obtenida en recursos gratuitos ofrezca plenas garantías. En este sentido, los centros de información son potenciales nodos para el control, selección y clasificación de fuentes de información y de referencia: diccionarios, enciclopedias, biografías, glosarios, atlas, tesauros, prensa, revistas electrónicas, bases de datos, sumarios electrónicos de revistas, directorios de recursos especializados...

Acceso al documento. Otro de los aspectos que más transforma Internet es el acceso al documento. Los principales instrumentos de búsqueda y localización son los catálogos de bibliotecas, así como bases de datos y buscadores.

La principal y más generalizada innovación es que Internet permite la consulta de los catálogos de bibliotecas desde cualquier lugar, conociendo la existencia de un documento y su estado de disponibilidad. Uno de los grandes logros es la consulta de los catálogos de bibliotecas, que plantean un paso más con la consulta simultánea a varios catálogos dispersos, aprovechando la tecnología del estándar Z39.50, protocolo que permite una consulta normalizada de los catálogos bibliotecarios. También podemos realizar consultas en bases de datos, y en los buscadores disponibles en Internet para la localización y consulta de los documentos.

Además, se prevé para el futuro nuevas formas de suministro de documentos, como el acceso al documento en texto completo y multimedia a partir de la consulta de catálogos o bases de datos, fusionándose de alguna manera con las revistas electrónicas.

Además de la consulta a catálogos o a bases de datos para conocer la existencia o estado de los documentos, el usuario tiene la posibilidad de comunicarse de forma remota para formular peticiones de préstamo o petición de fotocopias, reserva y/o renovación de documentos, recibir por correo electrónico avisos de relación de reservas, infracciones o atrasos, etc. Generalmente estos formularios electrónicos van acompañados de una página web explicativa de las condiciones del préstamo y/o de la remisión de documentación. La posibilidad de comunicarse con el sistema de automatización de forma remota se presenta como un importante beneficio que aporta la unión de un sistema automatizado de préstamo, un catálogo en línea por Internet y el uso del correo electrónico entre los usuarios.

Asimismo, Internet también ha permitido una agilización de estos procesos, sobre todo a partir de la disponibilidad de formularios mediante los cuales otras bibliotecas o centros de información pueden solicitar el préstamo de determinados documentos o la petición de fotocopias, así como el proceso de envío del documento digitalizado por correo electrónico. Generalmente estos formularios van acompañados de una página web explicativa de las condiciones del préstamo interbibliotecario y/o de la remisión de documentación.

Acceso al documento electrónico. Por otro lado, existe una gran cantidad de documentos electrónicos en formato ascii o imagen completa, conjuntamente con una oferta de servicios de alerta electrónica y de suministro rápido de copia del documento, de pago, que ofrecen el proceso de envío del documento digitalizado por correo electrónico. Este procedimiento es simple y rápido, evita toda manipulación de empaquetado y los retrasos postales, además la calidad del documento enviado supera a la fotocopia o al fax. Actualmente, existen importantes servicios de suministro de documentos, como Document Supply Centre de la British Library, Ebsco, etc.

Ello posibilita que la política de desarrollo de colecciones se pueda llevar a cabo pensando en opciones de acceso just-in-time frente a opciones de formación de la colección just-in-case. Es decir, no se dispondría de un fondo permanente pensado para atender a hipotéticas peticiones sino que el fondo se iría constituyendo en base a las peticiones efectivas de documentos. Esto es especialmente relevante para la literatura gris y las publicaciones en serie, y en el ámbito de los centros de documentación y las bibliotecas especializadas. Este enfoque exige una importante estrategia de control y localización de recursos electrónicos, que unifica en cierta medida el servicio de adquisiciones y el de referencia, y plantea una nueva orientación presupuestaria para afrontar los productos de pago.

\section{Producción}

El centro de información no es sólo un centro esencialmente usuario de recursos de información electrónica, sino que cada vez más, a esa faceta se le añade la vertiente productora de información digital, el Centro de información como productor y distribuidor de recursos y servicios de información en Internet.

De acuerdo con J. Tramullas, "la disciplina Diseño de Información se encarga de diseñar, crear y producir información digital, cuyo componente principal es el documento digital, orientado al usuario final. Se trata de una disciplina eminentemente pragmática, basada principalmente en la experimentación y en la adquisición de conocimientos mediante la práctica... El diseño de información se centra en la investigación de métodos para producir información digital, y en el diseño y creación final de esos productos. Se trata de una actividad princi- 
palmente informativa y comunicativa, cuyo destinatario final es el usuario/lector, y cuyo medio es el documento digital, construido dentro del marco de una arquitectura de la información... La arquitectura de la información reside en la organización de la información, entendiendo que ésta engloba tanto a la estructura propuesta para el contenido de la misma, como a los mecanismos necesarios para conocer y explorar esa estructura, y a la presentación visual de la misma. La creación de la arquitectura ha sido objeto de las propuestas de diferentes métodos. Sea cual sea el método utilizado, la arquitectura de la información obtenida debe ofrecer los siguientes resultados: organización de la información; sistema de navegación; sistema de etiquetado de contenido; sistema de búsqueda y recuperación. La creación de una arquitectura de la información suele adoptar la forma de proyecto de diseño, y utiliza los estudios de usuario y las técnicas de prototipo como factores clave de desarrollo".

Estructura informativa. El primer paso para el diseño y creación de una sede web con criterios de calidad es determinar qué información debe incluirse en la web y diseñar una estructura clara y sencilla de la información. Los dos ingredientes que hacen que una información digital sea valiosa son la forma y el contenido. Podemos tener una web con contenidos de alta calidad pero inutilizables por estar mal organizados, o estar exquisitamente diseñada pero ser poco comunicativa a los usuarios.

Debemos plantearnos el análisis y establecimiento de la estructura informativa básica de la página web a partir de los recursos informativos de la institución, del estudio de las necesidades de información de la organización y de los usuarios, y de la valoración de la información disponible en Internet sobre nuestro ámbito de actuación.

Antes de crear un proyecto web debemos planificar bien todo su contenido y saber las páginas que se integrarán en el proyecto. Una vez planificado, procederemos a la creación del sitio web bien organizado, para facilitar la administración de los elementos, la actualización constante de éstos y el funcionamiento correcto de los vínculos.

Respecto al contenido no es sólo importante la calidad de la información que contiene una sede web, sino también la cantidad. El medio digital contiene una capacidad (virtualmente) ilimitada como contenedor de información. No existe ninguna limitación para que una web no pueda ser la interfase unificada que proporcione acceso a grandes volúmenes de información. Proporcionar toda la información de calidad posible debería ser un objetivo claro cuando estemos involucrados en el diseño de una sede web, es decir, deberíamos preguntarnos la manera de conseguir que nuestra sede web tenga no solamente buena información, sino también mucha información, proporcionando toda la información de calidad posible.

Debemos preguntarnos qué información generada en el organismo o institución es susceptible de difusión: información sobre la estructura (horarios, direcciones, planos, etc.); información sobre el uso y normativas generales de acceso (reglamentos, descripción de servicios, etc.); información sobre las actividades y resultados (estadísticas, encuestas...); acceso a productos y servicios electrónicos (documentos, boletines, bases de datos, servicio de noticias, etc.); directorio de recursos externos (webs de interés); etc.

- Información estructural: dirección postal, teléfonos, fax, direcciones de correo electrónico, horarios, planos con ubicaciones, directorios de servicios administrativos y de personal, información sobre documentos y servicios que ofrecemos, etc.

- Información funcional: centrada en aquello que hay que conocer para hacer un uso correcto del centro y de sus servicios: normativas para la obtención de documentos, tarifas, normas generales de acceso, normativas de funcionamiento, reglamentos, actividades, proyectos, noticias y novedades, etc.

- Información formativa: con el fin de llevar a cabo una tarea formativa frente las diferentes posibilidades de acceso a la información: instrucciones y manuales de consulta de catálogos, bases de datos, etc.

- Información contextual: encaminada a mostrar a los usuarios qué hacemos y que resultados hemos obtenido: estadísticas o encuestas, novedades informativas incorporadas a la página web.

- Productos y servicios de información propios: bases de datos especializadas, boletines, catálogos, noticias de prensa, referencias legislativas, preguntas más frecuentes o FAQs (Frecuently Asked Questions), formularios electrónicos, sumarios electrónicos, listas de distribución para la difusión selectiva de la información, servicios de alerta informativa, publicaciones electrónicas, informes, jornadas, cursos, documentación oficial, etc.

- Recursos externos: directorio estructurado y actualizado de las fuentes de información o webs de interés disponibles en Internet sobre nuestro ámbito de actuación, y buscadores y directorios generales.

- Bibliotecas digitales: plantea la integración de los recursos de información, a través del acceso fácil y único a las fuentes de información internas y externas, disponibles de forma local o remota. Los centros de información están procediendo, por una parte, a digitalizar documentos de interés para los usuarios, a fin de formar una colección a la que se pueda acceder incluso fuera del horario del centro. Por otra parte, están ofreciendo enlaces a colecciones digitales de diferentes instituciones, para que sus usuarios puedan consultar y descargar obras. Esta doble acción de elaboración de repertorios y directorios de textos electrónicos se inscribe en la idea de que la biblioteca sin paredes es una realidad, ya que parte de sus fondos puede ser consultada desde cualquier lugar y en cualquier momento.

Sistemas de acceso. Debemos dotar a la sede web de un buen sistema de acceso a la información, a través de ayudas a la navegación y de recuperación de información. La estructuración de la información a través de la navegación: enlaces, menús, mapas táctiles, iconos, etc., resulta amigable y fácil de usar. En el caso de 
webs de cierta calidad, el sistema de navegación se complementa con estructuras jerárquicas organizadas en forma de árbol: mapas web.

Pero, no es suficiente un sistema de navegación para garantizar el acceso a la información, sino que cualquier sede medianamente compleja requerirá un sistema de recuperación para complementar al sistema de navegación y garantizar el acceso a la información. El sistema más fácil y accesible consiste en añadir un programa de indización al programa servidor de la web. El programa de indización permite que el cliente web pueda enviar preguntas al servidor, a través de un formulario. Un ejemplo a gran escala lo tenemos en los motores de búsqueda. Muchas sedes web utilizan un indizador de ese mismo tipo para permitir la recuperación de información. Otras opciones más complejas pasan por el uso de un programa completo de gestión de bases de datos.

Asimismo, es importante disponer de mecanismos interactivos que permitan a los usuarios reflejar sus opiniones, sugerencias o problemas, a través del correo electrónico y de listas de distribución. También, es interesante disponer de herramientas de medición para valorar quién accede, desde dónde y qué páginas de información se consultan más a menudo, con el objetivo de proceder a la retroalimentación del sistema.

Diseño gráfico. Además de los contenidos de calidad y los sistemas de búsqueda, recuperación y comunicación, es fundamental presentar un diseño gráfico atractivo, intuitivo, claro y uniforme. Es importante crear una guía de estilo que fije las bases tanto de estructura como de diseño de la página web, con el objetivo de mantener la homogeneidad de las páginas. Todas nuestras páginas deben tener una apariencia similar, combinando adecuadamente texto e imágenes, etc.

\section{Difusión}

Internet se caracteriza por su rapidez y facilidad de publicación y de difusión de la información, en comparación con los medios tradicionales. Este cambio ha permitido a cualquier organismo o persona convertirse en distribuidor de información, ofreciendo a los usuarios sus recursos y servicios de información. Además, hace posible compartir información entre instituciones e individuos, intercambiar información y conocimiento, que sigue siendo, a pesar del gran crecimiento de la comercialización, una característica permanente de la Red.

La difusión de la información se puede llevar a cabo de dos maneras: pasivamente, es decir, el centro publica documentos en la web y es el propio usuario quien busca, localiza y accede a la información, o de manera activa, siendo el centro el que envía a la dirección electrónica del usuario la información que necesita. En este último caso, el correo electrónico ha permitido la comunicación directa entre el profesional y el usuario final, con la consiguiente reducción de tiempo, espacio y costes.
Si bien el acceso a productos de información como bases de datos, boletines de novedades, etc., es ya bastante habitual, no pasa lo mismo con la presencia de servicios de difusión de información en Internet. El correo electrónico permite el establecimiento de perfiles de usuarios y el envío periódico de la información de su interés, pero existe una cierta cautela en la implantación de estos servicios a cualquier usuario, y generalmente se encuentra limitada a los usuarios de una comunidad institucional determinada.

Acceso directo por los usuarios. Un servicio cada vez más extendido y a la vez polémico es el acceso público a Internet, ya que tiene varios problemas: ¿deben ofrecerlo los centros públicos? ¿quién asume los costes? ¿qué recursos son accesibles? ¿cuánto y qué formación tiene que tener el personal para atenderlo eficientemente? Para su implantación es necesaria la elaboración de una normativa que contemple los siguientes aspectos:

Funcionamiento: limitación del tiempo de conexión, reserva de ordenador con antelación (día y hora), priorización de los usuarios.

Usos: generalmente se establece un filtro en el uso y un límite en el acceso a ciertos servicios, se prioriza la consulta de recursos de información y no se permiten las tertulias, webs de juegos, etc.

Seguridad: es fundamental instalar programas antivirus y escanear todos los disquetes que traigan los usuarios. Respecto a la prevención contra desconfiguraciones o daños de la información en la memoria del ordenador, hay que disponer de copias de seguridad de todas las instalaciones, limitar al máximo las funciones del ordenador que se puedan utilizar y no permitir la instalación de ningún programa.

Formación de usuarios: a través de cursos y/o de asistencia personalizada para ayudar a resolver problemas puntuales. Asimismo se plantea la formación de usuarios a través de Internet, con recursos dinámicos e interactivos de enseñanza, con gráficos, imágenes, ejemplos de texto completo, citas y todo tipo de material que proporcionen un entorno de aprendizaje real.

\section{Comunicación}

Las relaciones personales y la comunicación entre profesionales y usuarios también están cambiando. Se produce la mejora en la atención y comunicación con los usuarios de forma rápida y económica.

Atención a consultas de usuarios. Las relaciones personales y la comunicación entre profesionales y usuarios también están cambiando. Se produce la mejora en la atención y comunicación con los usuarios. A través del correo electrónico el organismo puede recoger las consultas y necesidades de los usuarios, de forma rápida y económica.

La opción más sencilla es facilitar la dirección de correo electrónico. Un sistema ligeramente más avanza- 
do es incorporar formularios para que el usuario pueda realizar sus peticiones y responder electrónicamente a la consulta. Encontramos desde formularios sencillos cuya finalidad es responder electrónicamente una consulta telefónica típica hasta modelos que recogen los mismos items que el formulario impreso.

Formación de usuarios. El objetivo principal es informar y formar a los usuarios en el uso y funcionamiento de todos los servicios y recursos disponibles en el centro de información que puedan ser de su interés. Con la implantación de las TIC, muchos centros de información ofrecen herramientas de formación a través de sus páginas web, como información del programa de formación o guías para el conocimiento de los recursos.

Comunicación interinstitucional. Asimismo, Internet se concibe como herramienta de comunicación interinstitucional, posibilitando los medios de comunicación con otras instituciones y organismos públicos y de investigación. Es una solución a los problemas de conexión de instituciones independientes pero homólogas, de lo que se deduce la conveniencia de utilizar Internet como un foro común de diálogo e intercambio de información, experiencias y conocimiento entre las instituciones.

En este sentido, destacar la creación de Comunidades Virtuales profesionales. Su objetivo es englobar a un grupo de instituciones y profesionales especializados en un mismo ámbito temático, con un sentimiento de conjunto, que comparta unas necesidades de información y de actualización de conocimientos para la difusión de información especializada, y que se encuentren siempre en completa interacción e intercambio de información, conocimientos y experiencias, a través de Internet.

Sus objetivos específicos son desarrollar un nuevo concepto de comunidad científica, cuyos miembros están en permanente contacto e intercambio de experiencias y continuamente actualizados en sus temas de interés, sin preocuparse del lugar geográfico en que se encuentren. Utilizar todos los servicios de Internet para desarrollarlos dentro de un mismo dominio a disposición de sus miembros. Crear una superestructura de contenidos altamente especializados, ofreciendo servicios integrados que no se encuentran en ningún otro lugar de la red. Establecer el concepto de trabajo cooperativo y dinámico entre sus miembros.

\section{Gestión interna}

Todavía poco generalizado es el servicio de información para la propia organización o Intranet, como redistribuidor dinámico de la información interna del centro (documentos internos, bases de datos corporativas, aplicaciones groupware, listas de distribución internas por grupos y funciones, tablones de anuncios...), a través de la aplicación de la tecnología web dentro de la organización. En este sentido, la Intranet puede ofrecer un modelo de organización virtual con canales de informa- ción estratificados para cada nivel de información, que permite un gran nivel de interacción entre equipos de trabajo que pueden estar en distintas ubicaciones.

La Intranet se debe concebir como un instrumento de comunicación y ello implica que haya una retroalimentación. Ha de ser rápida, es decir, la interfaz gráfica debe ser ligera y cargarse rápidamente. Los servidores deben adaptarse a las necesidades de la organización y a los hábitos de uso de la Intranet que en la misma se crean. El planteamiento debe estar claramente definido, ligado a la noción de usabilidad, y con ciertos elementos ineludibles: directorio, campo de búsqueda y noticias actualizadas. El más imprescindible es, sin duda, el contenido actualizado.

La dirección debe creer en la Intranet, sólo así la gente le otorgará la credibilidad que necesita. Además, no debe escatimar en recursos para promoverla, al menos en el proceso de implantación de la misma. Finalmente, debe ser creativa e idear campañas de marketing, y de participación para que los usuarios accedan a ella de un modo natural. Como aplicaciones y ventajas más destacadas se apuntan la realización de consultas internas, organización del trabajo, horarios, etc. por medio del correo electrónico, la publicación de manuales internos de procedimientos, el envío de ficheros adjuntos de documentos de trabajos en curso, listas de distribución internas para distribuir información de tipo laboral o profesional, etc.

La Intranet ofrece una cantidad considerable de beneficios:

- Optimiza la información unificándola y facilitando su tratamiento. Una Intranet bien desarrollada, otorga permisos diferentes a cada usuario para que sepa dónde y cómo debe publicar dicha información.

- Acelera el paso de la gestión de la información a la gestión del conocimiento. Con una Intranet es el usuario el que se informa para llevar a cabo correctamente su tarea.

- Está activa las 24 horas del día, siete días a la semana.

- Es una herramienta de grupo. Los foros, los tablones de anuncios estratégicamente colocados en la Intranet son realmente útiles para llevar a cabo la tarea.

- Ahorro económico, en el uso de papel, teléfono.

- Cohesión de los grupos.

- Información actualizada, reciente. Conseguir que la Intranet sea una fuente fiable y actualizada de información.

- No se entorpece la labor de otros compañeros. Los tutoriales son un buen medio para adquirir conocimientos rápidamente, además el e-mail constituye una herramienta ideal para la colaboración.

- Información por escrito (almacenable y consultable). La información queda registrada de forma escrita e invariable, mucho más fidedigna para ser consultada.

- Más información dado que es más fácil enviarla. Con la Intranet, la información generada en la organización aumenta considerablemente. Comunicarse a través de los medios electrónicos resulta sencillo.

- Vehículo de comunicación con la dirección. Consigue que el personal suba a la dirección y no que la dirección baje. 
- La Intranet es una red basada en el protocolo TCP/IP y que goza de las mismas ventajas: conectividad, apertura del sistema...y escalabilidad. Por eso la Intranet que crece más allá de la propia organización se puede convertir en Extranet.

- Fácil uso, ya que la Intranet es una interfaz gráfica como cualquiera a la que se acceda desde el navegador del ordenador.

\section{Dificultades}

Sin embargo, tampoco debemos considerar a la Red como la solución de todo. Hay que situar a Internet exactamente en el punto en que se encuentra, desmitificándola y resaltando lo que ahora mismo son sus principales problemas. Ello ayuda a no crear falsas expectativas.

Lentitud. A veces la lentitud de acceso puede restar eficacia al sistema. Los motivos se deben fundamentalmente a tres factores: Equipamiento informático del usuario poco potente para la utilización de las abundantes imágenes existentes en las páginas web. Saturación de las redes, ya que éstas no han variado en la misma proporción que la gran cantidad de servicios que circulan en la actualidad. Saturación o mal funcionamiento del servidor, provocada por la limitación del ancho de banda, puertos y horarios de los servidores.

Calidad de la información. Hay que tener en cuenta que Internet no es una única fuente, sino que en ella confluyen millones de fuentes individuales y una gran variedad de documentos que van desde páginas personales hasta libros digitalizados. Por otro lado, nadie hace un control de calidad de esta "colección". Determinar el valor de los recursos de información es uno de los principales problemas de contenido que se plantean. Hay que hacer la transición desde los mecanismos de evaluación de las obras de referencia clásicas a las nuevas fuentes disponibles en la red. En este sentido, hay que destacar la importancia de la evaluación, descripción y representación de documentos digitales.

Dificultades en la localización de la información. Falta organización, consistencia y fiabilidad. Por un lado, es difícil encontrar sistemas paralelos a descriptores, materias o clasificación, aunque existen intentos de normalización como la indización de los recursos electrónicos a través de los metadatos. Tampoco existe un sistema común de búsqueda ni un índice exhaustivo universal. Además, las fuentes existentes no son estáticas ni estables, ya que tan pronto están disponibles como desaparecen.

Autenticidad. Una de las características de este nuevo entorno es que cualquiera puede constituirse en editor y distribuidor de una obra, lo cual genera una falta de garantías de permanencia y autenticidad. Es posible que, a medida que las editoriales tradicionales vayan entrando en esta nueva forma de edición, la situación mejore. Actualmente ya son muchos los documentos electrónicos que tienen ISBN o ISSN, aunque de momento la confusión es aún grande.
Autoridad. El anonimato de las comunicaciones dentro de Internet afecta a la edición electrónica de forma poco favorable, ya que una de las premisas de las publicaciones de calidad es que hayan sido evaluadas, hecho que confiere a los autores una autoridad respecto a su contenido.

Costes: la financiación pública del acceso a Internet en centros públicos y de investigación ha creado una sensación de gratuidad de este medio, sin embargo cada vez son más frecuentes los servicios de pago presentes en la red.

En la página web <http://www.TheEndOfFree.com> se documentan casos de servicios de información gratuitos que están pasando a ser de pago. Parece que después de la caída de las empresas punto.com y de la correspondiente publicidad electrónica se ha producido una tendencia a cobrar, cuya extensión y éxito están todavía por ver.

En febrero de 2002 se aprueba el Proyecto de Ley de Servicios de la Sociedad de la Información y Comercio Electrónico <http://www.setsi.mcyt.es/lssi/lssi_ home.html>. Conviene conocer esta ley, ya que regula los servicios prestados por Internet, de los cuales son clientes habituales los centros de información. Además, buena parte de las actividades reguladas son realizadas por las bibliotecas y, dependerá de la consideración de actividad económica que puedan tener éstas, para que la ley les afecte como prestadores de servicios.

Derechos de autor. El entorno digital ha provocado incertidumbre sobre si es suficiente la protección que otorga la legislación vigente a los derechos de autor. Las posibilidades de la tecnología digital y las redes de comunicación en cuanto a la transmisión, reproducción y manipulación de la información parecen desbordar las previsiones normativas del entorno analógico, provocando cierta inquietud tanto en productores y distribuidores como en sus usuarios.

En 1997 se inició un proceso legal a partir de la Propuesta de Directiva Europea relativa a la armonización de determinados aspectos de los derechos de autor y derechos afines en la sociedad de la información COM (97) 628 final, 97/0359 (COD), DOCE C 108, de 7 de abril de 1998. Ello provocó que determinadas asociaciones profesionales elaboraran propuestas de revisión. El colectivo bibliotecario europeo elaboró una propuesta común de revisión a la Propuesta de Directiva. La iniciativa fue impulsada por EBLIDA (European Bureau of Library, Information and Documentation Associations), a través del proyecto europeo ECUP+ (European Copyright Users Plattform) <http://www.eblida.org/>. En España, lideró esta actuación el Grupo de trabajo de Bibliotecas y derechos de Propiedad Intelectual de FESABID (Federación Española de Sociedades de Archivística, Biblioteconomía y Documentación) y del COBDC (Collegi Oficial de Bibliotecaris-Documentalistes de Catalunya), adaptando a nuestro contexto normativo la posición bibliotecaria europea. 
La Comisión presentó la propuesta el 27 de enero de 1998. El 10 de febrero de 1999 el Parlamento aprobó la propuesta de la Comisión con 58 enmiendas. La Comisión adoptó una propuesta modificada el 21 de mayo de 1999. En diciembre de 2000 apareció la última de las propuestas sobre dicha Directiva (DOCE C344), y en febrero de 200 I se publicó el Dictamen de la Comisión sobre las enmiendas del Parlamento europeo a la posición común del Consejo sobre la propuesta de la Directiva COM (200I) I 70 final.

La publicación de la Directiva 2001/29/CE, del Parlamento Europeo y del Consejo, de 22 de mayo de 2001 , relativa a la armonización de determinados aspectos de los derechos de autor y derechos afines a los derechos de autor en la sociedad de la información (DOCE LI67/I0, 22-6-200I) marca el final de largos debates y numerosas revisiones de este texto legislativo <http://europa.eu.int/eur-lex/es/lif/dat/ 200I/es_30 I L0029.html>.

Además, se ha abierto el período de transposición a las legislaciones nacionales de los distintos Estados miembros de la Unión Europea. Nuestra legislación sobre derechos de autor es regulada por el Real Decreto legislativo I/1996, de 12 de abril (BOE nº 97, de 22 de abril), que reconoce, en su artículo 37, una excepción para bibliotecas, museos, archivos, hemerotecas, fonotecas o filmotecas de titularidad pública o que pertenezcan a entidades de interés general de carácter cultural, científico o educativo sin ánimo de lucro, o a instituciones docentes integradas en el sistema educativo español.

\section{El Profesional de la información}

Ante todo ello, ventajas y problemas, es fundamental el papel del profesional de la información, tanto en el conocimiento y explotación de los recursos disponibles en la Red como en la producción y organización de los recursos informativos digitales, y en la selección y evaluación de las fuentes de información.

El desarrollo de Internet representa el mayor desafío experimentado para los profesionales de la información, ya que exige un replanteamiento de los conocimientos tecnológicos, de las actitudes mentales, de las funciones y labores tradicionales, así como una nueva definición de su papel.

Ello nos obliga a estar al día de las nuevas tecnologías, exige un reciclaje, una formación teórica-técnica previa, a través de cursos, jornadas, lecturas profesionales..., y una constante dedicación práctica en el conocimiento y explotación de los recursos contenidos de la Red. El profesional tiene la ineludible obligación de la formación continua para convertirse en un especialista que sepa en todo momento moverse por la Red y encontrar la información buscada. De lo contrario pronto podremos ser desplazados por otros profesionales conocedores de las posibilidades y usos de los nuevos medios de comunicación.

Además, la enorme disponibilidad de información, y su fácil acceso por los usuarios, provoca que los profesionales puedan tener una sensación de pérdida de su papel como intermediarios de la información. Internet y sus servicios hace que los usuarios puedan acceder a fuentes de información sin nuestra mediación.

Sin embargo, las Tecnologías de la Información y las Comunicaciones (TIC) no sólo representan un reto para los profesionales, sino una gran oportunidad para demostrar que nuestras aportaciones técnicas y metodológicas pueden dar un valor añadido esencial a la sociedad de la información. El profesional tiene ahora la oportunidad de demostrar su capacidad en la selección de las fuentes, convirtiéndose en guía cualificado y organizador de las vías de acceso a la información más apropiada, mediante el conocimiento, utilización y organización de los recursos de la Red, incidiendo en la evaluación de las fuentes de información electrónicas, criterio que no puede ser suplido por ningún sistema de búsqueda electrónica.

El papel del profesional no desaparecerá, sino que se transformará y se enriquecerá, afectando a corto y medio plazo a la totalidad de las tareas que venimos desarrollando actualmente, modificando las tareas tradicionales y apareciendo otras nuevas como recopilar, organizar y estructurar la información que se encuentra en Internet.

Marta Torres señala que debido al fenómeno tecnológico que estamos viviendo, nos encontramos en un mundo que nos pide no ya que informaticemos nuestros servicios, sino que desarrollemos servicios nuevos a la luz de las innovaciones tecnológicas.

\section{Bibliografía}

ANGLADA, L.M. Biblioteca digital imejor, peor o solo distinto? En Anales de Documentación, n³, 2000, p.25-39 <http://www.um.es/fccd/anales/ad03/AD02-2000.PDF>

BORREGO HUERTA, A. Bibliotecarios reales para bibliotecas virtuales: la necesidad de asistencia humana en el entorno digital. En Métodos de Información, $n^{\circ}$ 48, noviembre 2001 <http://www. metodosdeinformacion.com/>
Directiva 200I/29/CE, del parlamento Europeo y del Consejo, de 22 de mayo de 200 I, relativa a la armonización de determinados aspectos de los derechos de autor y derechos afines a los derechos de autor en la sociedad de la información. (DOCE LI67//0, 22-6-200I) <http://europa.eu.int/eur-lex/es/lif/dat/200l/es 30 | L0029.html>

DOMENECH OSETE, B. Del átomo al bit o de lo físico a lo virtual. En Métodos de Información, $n^{\circ}$ 48, noviembre 2001 $<$ http://www.metodosdeinformacion.com/> 
ESTIVILL, A., ABADAL, E. Acceso a los recursos web gratuitos desde las bibliotecas. En El Profesional de la Información, vol. 9 , n. I I, noviembre 2000, p. 4-20

FROEHLICH, T.J. Las preocupaciones éticas de los profesionales de la información acerca de internet. En Educación y bibliotecas, año I I, n. 106 (noviembre 1999), p. 6 I-69 Traducción de Paco Vidarte.

GARCÍA MARCO, F.J. Servicios de información en la World Wide Web: una nueva frontera para los docentes del área de biblioteconomía y documentación. En Cuadernos de Documentación Multimedia, n 6-7, 1997-1998 <http://www.ucm.es/info/ multidoc/multidoc/revista/cuad6-7/garmarza.htm>

GONZÁLEZ F-VILLAVICENCIO, N. Gestión y optimización de los recursos de información en Intranets corporativas. En Boletín $\mathrm{PH}, \mathrm{n}^{\circ} 24$, septiembre 1998

GONZÁLEZ LORCA, J, RODRÍGUEZ MUÑOZ, J.V. La tecnología de flujo de trabajo en el contexto de la biblioteca digital. En Anales de Documentación, vol. 5, 2002 <http://www.um.es/fccd// anales/ad05/ad0500.html>

GRYNBAUM, V. Le droit de reproduction à l'heure de la société de l'information. En Juriscom.net |3-|2-200| < http://www. juriscom.net/pro/2/da200 | | 2 |3.pdf $>$

Information Architecture <http://uncle-netword.com/articles/ writeweb3.html>

II Jornadas de Bibliotecas Digitales: Almagro, noviembre 200 I. En Métodos de Información, $n^{\circ} 48$, noviembre 2001 <http://www. metodosdeinformacion.com/>

KUNY, T.; CLEVELAND, G. La biblioteca digital: mitos y retos. En Métodos de Información, $n^{\circ}$ 48, noviembre 200I <http://www. metodosdeinformacion.com/>

LÓPEZ DE PRADO, M.R., PALAREA PERRIER, J.M. Internet para pequeñas bibliotecas: hágalo usted mismo. En 2as. Jornadas Andaluzas de Documentación Jadoc'99, p. 63-84

MERLO VEGA, J.A. 50 aplicaciones bibliotecarias de Internet. En Educación y biblioteca, noviembre 1999, n. 106, p. 38-47 <http://exlibris.usal.es/merlo/escritos/aplica.htm>

MERLO, J.A., ONTORIA, M.A., PÉREZ IGLESIAS, J. Internet una herramienta bibliotecaria. En Educación y biblioteca, año I I, n. 106, noviembre 1999
OLVERA LOBO, M.D. Internet y la Sociedad de la Información. En Boletín de la ANABAD, vol. L, n. I, 2000, p. 129-142

PAZ YANES, C. Bibliotecas digitales: algo viejo, algo nuevo y algo prestado. En Métodos de Información, n 48, noviembre 2001 $<$ http://www.metodosdeinformacion.com/>

PÉREZ ALARCÓN, A., SERRANO MUÑOZ, J. Tecnologías de la información aplicadas a los servicios bibliotecarios. En Cuadernos de Documentación Multimedia, n.8, 1999 <http://www.ucm.es/ info/multidoc/multidoc/revista/num8/bib-vir.html>

RADER, H.B.; FERÁNDEZ TOLEDO, P., trad. Alfabetización informacional en el entorno del servicio de referencia: Preparándonos para el futuro. En Anales de Documentación, n³, 2000, p.209216 <http://www.um.es/fccd/anales/ad03/AD I2-2000.PDF>

RODRÍGUEZ GAIRÍN, J.M.; SERRANO, J. EI Web com a mitjà d'estructuració i distribució d'informació bibliotecària. En 5es. Jornades Catalanes de Documentació: biblioteques, centres de documentació i serveis d'informació, 1995, p. 539-548

Seminario Producción y lectura de información digital: la cultura de los contenidos. Cursos de Verano de la Universidad de Zaragoza, julio 200 I. Directores Jesús Tramullas Saz y Miguel Ángel Esteban Navarro (Departamento de Ciencias de la Documentación de la Universidad de Zaragoza) < http://digital. docunautica.com>

Seminario Virtual de Información para Archivos, Bibliotecas y Museos: Marketing de Servicios. En Biblios <http://bibliotecas. rcp.net.pe/biblios/>

SORLI ROJO, Á., MERLO VEGA, J.A. Suministro de documentos en Internet. En Revista Española de Documentación Científica, julsept. 1998, vol. 21 , n. 3, p. 319-328 <http://exlibris.usal.es/merlo/ escritos/redcsumi.htm>

SORLI ROJO, Á., MERLO VEGA, J.A. Bibliotecas Digitales (I): colecciones de libros de acceso público. En Revista Española de Documentación Científica, enero-marzo 2000, vol. 23, n. I, p.91-103 <http://exlibris.usal.es/merlo/escritos/redcbdl.htm>

SORLI ROJO, Á., MERLO VEGA, J.A. Bibliotecas digitales (II): directorios de recursos. En Revista Española de Documentación Científica, abril-junio 2000, vol. 23, n. 2, p.213-220<http://exlibris. usal.es/merlo/escritos/redcbd2.htm>

TRAMULLAS, J. Diseño y arquitectura de la información $<$ http://www.tramullas.com/infodesign/> 